\title{
Design of passive heat sinks to power semiconductor with the cesaro curve
}

\author{
Diseño de disipadores de calor pasivo para semiconductores de potencia con la curva de \\ cesaro
}

\section{Luis Carlos Ruiz-Cárdenas (iD) ${ }^{1}$, Luis Eduardo Llano-Sánchez (D) ${ }^{1 *}$, Darío Manuel Domínguez-Cajeli (iD) ${ }^{2}$, Martha Cecilia Melo de Alonso (iD) ${ }^{2}$, Carolina González-Rodríguez (iD) 1}

${ }^{1}$ Facultad de Ingeniería, Programa de Ingeniería Civil, Universidad Militar Nueva Granada, Sede Campus, Km. 2 vía Cajicá - Zipaquirá. C.P. 250247. Cundinamarca, Colombia.

${ }^{2}$ Facultad de Ciencias Básicas y aplicadas, Departamento de Matemáticas, Universidad Militar Nueva Granada, Sede Campus, Km. 2 vía Cajicá - Zipaquirá. C.P. 250247. Cundinamarca, Colombia.

\section{CITE THIS ARTICLE AS:}

L. C. Ruiz, L. E. Llano, D. M. Domínguez, M. C. Melo and Carolina González "Design of passive heat sinks to power semiconductor with the cesaro curve", Revista Facultad de Ingeniería Universidad de Antioquia, no. 97, pp. 87-92, Oct-Dec 2020. [Online].

Available: https :

//www.doi.org/10.17533/ udea.redin. 20200162

\section{ARTICLE INFO:}

Received: November 14, 2017 Accepted: January 31, 2020

Available online: February 03, 2020

\section{KEYWORDS:}

Thermal analysis; heat sinks; Cesaro curve; ANSYS; power semiconductors

Análisis térmico; disipador de calor; curva de Cesaro; ANSYS; semiconductores de potencia

\begin{abstract}
In the design of electronic circuits, stands out the power stage, which is responsible of increasing the signal characteristics, as current and voltage, for an appropriate performance of the device to fabricate. However, this stage is composed of elements like transistors, which may have a low performance, due to the undesired temperature increase, as a result of reaching the desired power. To mitigate the loss of power and with it, the temperature rise, the management of heat sink is proposed, in order to keep the work of the power stage at a stable level and avoid thermal fractures within the circuit. This manuscript presents the obtained results of the thermal analysis in finite elements of the heat sink with fins in the form of a Cesaro curve, for power semiconductors, which evidence the increase in the heat flow, with respect to the commercial ones and so, facilitate the heat evacuation for conditioning the voltage and/or current.
\end{abstract}

RESUMEN: En el diseño de circuitos electrónicos se destaca la etapa de potencia, la cual se encarga de aumentar las características de una señal, como la corriente y el voltaje, para un apropiado funcionamiento del equipo a desarrollar. Sin embargo, esta etapa está conformada por elementos como los transistores, los cuales pueden presentar un bajo rendimiento, debido al aumento indeseado de temperatura, como consecuencia de alcanzar la potencia deseada. Para mitigar la perdida de potencia y con ello, la elevación de temperatura, se propone el manejo de disipadores de calor, con el propósito de mantener el trabajo de la etapa de potencia en un nivel estable y evitar fracturas térmicas dentro del circuito. En el siguiente trabajo, se exponen los resultados obtenidos del análisis térmico en elementos finitos del disipador de calor con aletas en forma de curva de Cesaro, para semiconductores de potencia, lo cual evidenció el aumento en el flujo de calor, respecto a los comerciales y de este modo, facilitar la evacuación de calor para el acondicionamiento de la tensión y/o corriente.

\section{Introduction}

The development of electronic circuits require the continuous use of daily tasks, as demand the manipulation of autonomous and teleoperated devices, as also the prolonged use of mobile devices. Thereby, it is possible to infer, that the use of those devices, sometimes requires

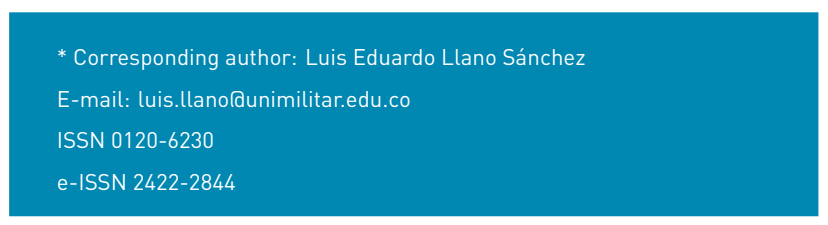

the use of high levels of voltage and/or current, which could obtain losses by generation of heat energy, therefore it would alter the performance of the device and could show deterioration in the internal circuits $[1,2]$. To reduce the heating of the devices inside, the use of heat sinks is proposed, for power semiconductors. These elements have the quality of absorbing the heat and in this way lead it to the outside, avoiding the possible damage of the circuit as of the elements that compose it [3-5].

Other application of heat sinks is in hybrid vehicles, arranged for fluid cooling, where the design is validated 
from analysis in the finite elements with variables such as the amount of fluid to cool and the speed of circulation [3]. In lighting devices [6], heat sinks with fins with " $T$ " or " + " shapes are used [7], as well as inclined fins for natural convection [8]. In the same way, alternative to conventional geometries have been developed such as the cookie structure [9], which is coupled to the integrated ones through protuberances on the surface of the semiconductor packing $[10,11]$. In the development of printed circuits, heat sinks are integrated into the processors, in order to take advantage of the energy required by each of the elements present on the plate $[12,13]$. In the telecommunication area, antennas with fractal geometries have been developed, which can fulfill the function of a heat sink and can also increase communication decibels and amplify Radio Frequency energy [14].

Previous to do the production of the heat sinks, it is necessary to implement the finite elements analysis, in order to analyze the heat flow [3], or the mass flow analysis, to proceed to apply optimization methods to improve results regarding the thermal, physical and electrical characteristics $[15,16]$. As a clear example, it can be observed in the development of computers, where it is necessary to predict the behavior of the non-uniform heat inside the CPU (Central Processing Unit), to reduce the temperature in the plates of the CPU [17-19] and favor storage in magnetic mediums with energy assistance [20].

In the present work, the results obtained are presented with the analysis of heat flow by finite elements, of a heat sink with fins in the form of the Cesaro curve, for transistors with packaged TO -220 . This transistor is taken as an example due to its common use in engineering applications to obtain the necessary current for actuators, such as motors. Initially, the methodology that was carried out to perform the analysis of the heat flow of the suggested heat sink is proposed, where the use of the geometry of the Cesaro curve is explained [21], with the aim of increasing the surface of the heat sink and improving the heat evacuation outward.

Then, it is proceeded to explain the result obtained from performing the thermal flow analysis at a stationary state with the finite element software (CAE) ANSYS. There, the heat flux comparison of a commercial fin heat sink is performed with the fractal geometry heat sink by means of natural convection. This work is oriented at advancing the research process to carry out the implementation of geometrical structures of nature or fractal in everyday and engineering applications, with the purpose of improving processes such as heat transfer and thus contributing to the continuous growth of engineering processes.

\section{Methodology}

With the integration of the engineering with fractals geometries, it has been possible to describe the behavior of heat flow [22], as well as computational algorithms that have been developed for digital image processing [23]. Another clear example is in the area of telecommunications, with the development of antennas to improve wireless communication, increasing the bandwidth and improving the communication efficiency $[24,25]$, similarly in the area of medicine, it has been used for the purpose of identifying the morphological structure of organs such as the kidney and the brain $[26,27]$. Similarly, postsurgical tissue recovery processes have been performed [28] and software development for medical image analysis [29].

In the mechanical engineering field, the analysis of fractures in polycrystalline materials is carried out, based on the fractal dimension, to reduce the fracture behavior and thus reduce it $[30,31]$. Another use can be detailed in improving the understanding of ceramic surfaces with respect to metals, where stiffness and texture are taken into account [32].

In order to carry out the thermal analysis by finite elements of the heat sink with fins in forms of a Cesaro curve, initially, the growth procedure of the Cesaro curve is performed, as shown in Figure 1.

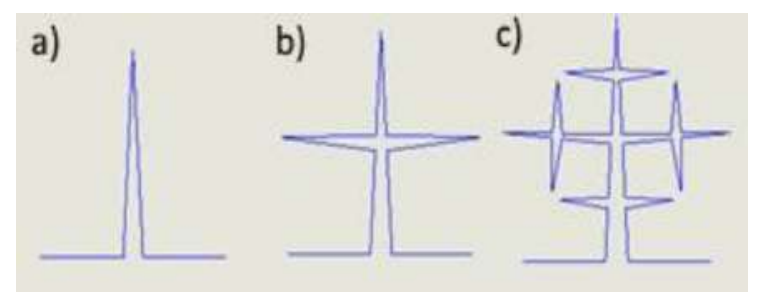

Figure 1 Cesaro curve growth to al generation 0 , b) generation 1, c) generation 2. (Source: own elaboration)

The mathematical analysis of the Cesaro curve is obtained from the Equation 1, which requires knowing the initial length of the main branch $(\mathrm{Lo})$ and the generation to be obtained $(n)$, from it you can get the length $(L)$ of each of the sub-branches that are obtained in each iteration [33].

$$
L=L o *\left(\frac{1}{2}\right)^{n}
$$

In the design of heat sinks, it is necessary to take into account the power to be dissipated $\left(P_{t}\right)$ which is generated during the task of the semiconductors. For this, Equation 2 is taken into account, which requires knowing the power on the load $\left(P_{r}\right)$ and the power supplied $\left(P_{c c}\right)$

$$
P_{t}=\frac{P_{c c}-P r}{4}
$$


Where $P_{r}$, Equation 3, requires knowing the load resistance $\left(R_{L}\right)$ and the amplitude of the input signal $\left(V_{p}\right)$ :

$$
P_{r}=2 * \frac{V_{p}^{2}}{R_{L}}
$$

To found $P_{c c}$, Equation 4 , it is necessary to take into account the power supply by the booster in direct current $(E)$

$$
P_{c c}=\frac{8 * E * V_{p}}{R_{l} * \pi}
$$

Now, it is the heat sink-air resistance $\left(R_{d a}\right)$, which is obtained from the Equation 5 and requires knowing the maximum temperature that the transistor $\left(T_{j}\right)$ can reach, the ambient temperature $\left(T_{a}\right)$, the power to dissipate $\left(P_{c c}\right)$, the capsule - union resistance $\left(R_{j c}\right)$ and the union - sinks resistance $\left(R_{c d}\right)$.

$$
R_{d a}=\frac{T_{j}-T_{a}}{P_{c c}}-\left(R_{j c}-R_{c d}\right)
$$

With the use of the heat sinks in the power transistors, it is possible to maintain its operation at a stable level and prevent the low performance due to the power that dissipates as heat [34]. Then, the commercial heat sink is used for transistors with packaged TO -220 , in order to adjust the fractal geometry of the Cesaro curve to each fin.

Therefore, to do the design of the fins with the Cesaro curve, the generation 2 described in Figure 1 is taken into account, with the purpose of proposing two kind of heat sinks, the first one with longitudinal continuous fins and the second with split fins, as shown in the Figure 2.

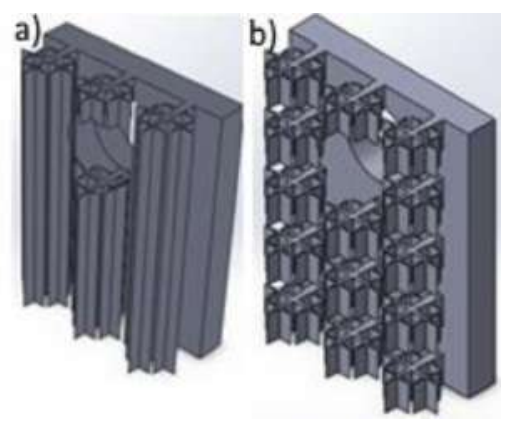

Figure 2 Heat sinks with fins in Cesaro curve form with the second generation, where a) is the continue longitudinal fins and b) is the divided fins (Source: own elaboration)

This is done by stimulating finite elements, with the computational tool ANSYS, to identify the heat flow that would be presented by each of the designs previously proposed. For this, it is considered that the heat sink is passive; it is configured as a natural convection process, without the need to use fans. It will also be simulated by assigning aluminum as semiconductor material and in the middle of the fins air is flowing at room temperature.

\section{Results}

In order to obtain the heat flow of the commercial heat sink with continuous and split fins and of the sinks designed with Cesaro curve fins, the ANSYS software indicates that the thermal analysis is to be carried out at a steady state (steady - state thermal), then the material corresponding to the heat sink is assigned. In this case, the different materials that are used are taken into account, which are cooper and aluminum. But to have a better consistency with reality, anodized aluminum was chosen, because of its thermal properties and it costs less than copper.

Then, the initial environment temperature $\left(25^{\circ} \mathrm{C}\right)$ and the type of fluid that would surround the heat sink are indicated, for this case is air. Finally, it is taken into account that part of the heat sink will be in contact with the power semiconductor and the analysis is carried out, whose results can be appreciated in the Figure 3.

In order to have a better understanding of the results, Figure 4 is presented, indicating how the heat flow can increase by using split and continuous fins for the second generation of the fractal geometry of the Cesaro curve.

\section{Result analysis}

With the results, it is possible to appreciate the increase of the heat flux in the heat sinks with fins in Cesaro curve of second generation both continous and divided. This can improve the operation conditions of the power semiconductors, increasing the power capacity without damaging the physical structure of both the transistor and the plate where it is installed. In the same way, the results can be reached, because there is a better air flow between the fins and the increase of the sink surface of the heat sink.

With the development of this work, it is possible to increase the heat flux between the heat sink, the junction and the power semiconductor, due to the enlargement of the sink surface, giving the ability to allow a better flow of heat into the environment by the process of natural convection. In the same way, it is possible to deduce that the use of the Cesaro curve, with higher generations is possible to obtain a great increase of the heat flux, giving the capability to the transistors function in desired operating ranges without hainge damage by the high temperature produce.

Conventional rectangular fins are used by normal commercial dissipaters as shown in Figure 4, heat dissipation is lower than that obtained with fractal fins with Cesaro curve. The first proposal is divided into 


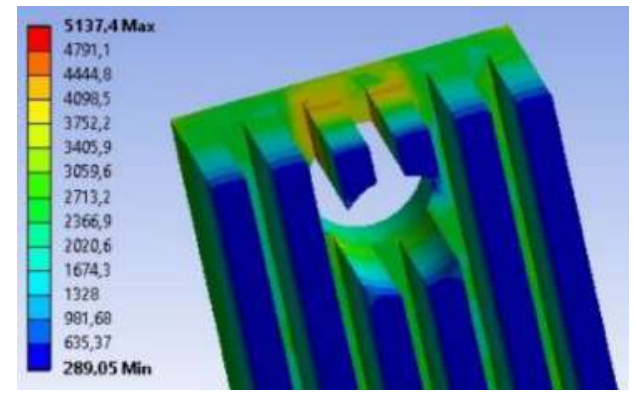

(a)

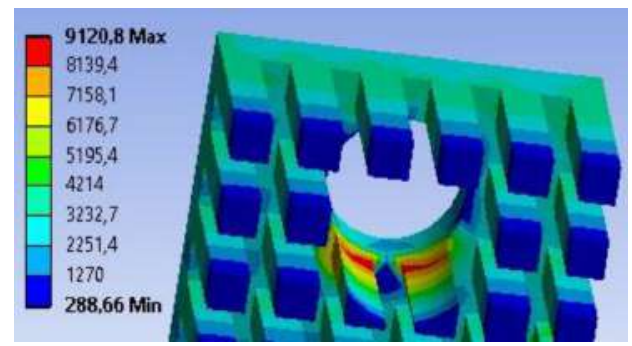

(c)

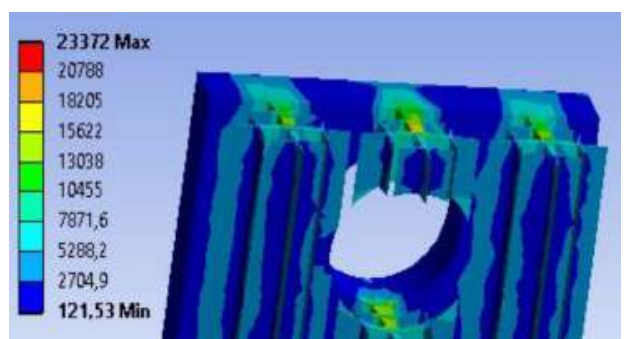

(b)

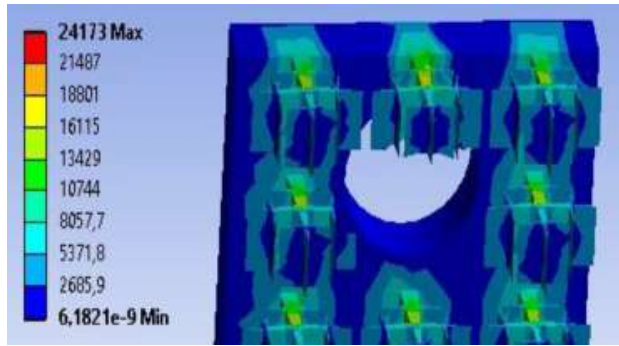

(d)

Figure 3 Results obtained of the finite elements analysis of the heat sinks, for longitudinal fins al commercial, b) fins in Cesaro curve form of second generation, with divided fins c) commercial and d) fins in Cesaro curve form of second generation. (Source: own elaboration)

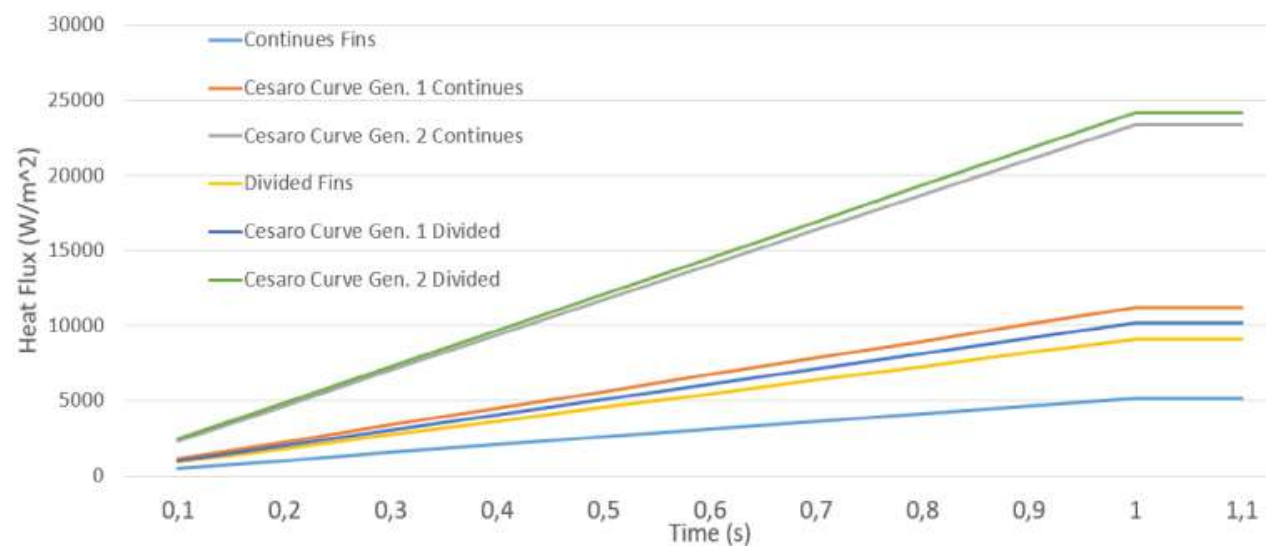

Figure 4 Behavior of the heat flux to each sink both commercials and designed proposed (Source: own elaboration)

rectangular fins which already improve heat transfer, Now, when the fractal fins with Cesaro curve are analyzed, the increase in heat flow in the sink compared to the previous ones is evident.

First and second generation Cesar curves were analyzed (Figure 1), finding that the second generation is the most efficient in continuous fin; however this same split fin is more efficient than continuous.

Cesaro's curve was chosen because the seed of the construction is a classic triangular fin and as fractals have a geometric property of increasing the area significantly with a moderate increase in volume, it is corroborated that the heat transfer in the heat sink is increased due to the increase in the area of convection by the fractal design of the fins. This was verified by the simulation performed with finite elements with ANSYS, which in turn required the construction in CAD of the second generation CESARO curved fins sink.

\section{Conclusions}

It is possible to conclude with the development of this work, that the heat flux between the heat sink, the junction and the power semiconductor can be increased, due to the enlargement of the sink surface, giving the ability to allow 
a better flow of heat into the environment by the process of natural convection. In the same way, it is possible to deduce that with the use of the Cesaro curve, with higher generations is feaseable to obtain a great increase of the heat flux, giving the capability to the transistors function in desired operating ranges without having damage by the high production temperature.

It is possible to conclude that as fractal theory asserts that on any scale physical phenomena such as heat flow behave similarly on any scale. This phenomenon functioned in a similar way at the nano, micro or macro level, which the authors consider the most important contribution of this research, since innovation in engineering designs with fractal geometries can improve the efficiency of different applied engineering phenomena.

Finally, its possible to continue with the analysis of fractal geometries applications in works of engineering at macro level, where it is probable to improve different process that are limited by variation of temperature, humidity, solar radiation among others. Giving way to the development of future works where it could contribute in the improvement of activities to industrial level and personal of the daily life.

\section{Declaration of competing interest}

None declared under financial, professional and personal competing interests.

\section{Acknowledgments}

To the vice-rectory of research of the Universidad Militar Nueva Granada, who managed the financing the research project development INV_ING 2117 tittle; “Diseño de estructuras fractales para ingeniería", during the 2016.

\section{References}

[1] S. Sakurai and et al, "Design and Development of Lower Divertor for JT-60SA," in International Conferences on Fusion Energy, Naka, Korea, 2010, pp. 1-7.

[2] H. Chi, J. Jang, H. Yeh, and M. Wu, "The heat transfer characteristics of liquid cooling heatsink containing microchannels," International Journal of Heat and Mass Transfer, vol. 54, no. 1, January 152011. [Online]. Available: https://doi.org/10.1016/j.ijheatmasstransfer. 2010.09.066

[3] V. Pickert, H. Cheng, L. Pritchard, and D. J. Atkinson, "An experimental and computational study of water cooled heatsinks for HEV's," in $5^{\text {th }}$ IET International Conference on Power Electronics, Machines and Drives (PEMD 2010), Brighton, United Kingdom, 2010.

[4] C. C. Davidson, R. M. Preedy, J. Cao, C. Zhou, and J. Fu, "Ultra-high power thyristor valves for HVDC in developing countries," in $9^{\text {th }}$ IET International Conference on AC and DC Power Transmission IACDC 2010), London, United Kingdom, 2010.
[5] X. Zhou and et al, "High-frequency EMC design verification through full-wave simulations and measurements in Reverberation Chamber," in 2013 IEEE International Symposium on Electromagnetic Compatibility, Denver, Colorado, 2013, pp. 299-305.

[6] A. P. Van de Ven, "Lighting device with flexibly coupled heatsinks," Patent W02 012109 060A3, Nov. 1, 2012.

[7] M. D. McClure and A. J. McClure, "Slotted heatsinks and systems and methods related thereto," U.S. Patent US20 140049 964A1, Feb. 20, 2014

[8] K. T. Park, H. J. Kim, J. Yoo, M. G. Lee, and D. Kim, “Experimental study on effect of inclination angle on natural convection from cylindrical heatsinks with plate fins," Transactions of the Korean Society of Mechanical Engineers B, vol. 39, no. 4, April 2015. [Online]. Available: https://doi.org/10.3795/KSME-B.2015.39.4.343

[9] S. Tian, T. M. Cipolla, and P. W. Coteus, "Coined-sheet-metal heatsinks for closely packaged heat-producing devices such as dual in-line memory modules (DIMMs)," U.S. Patent US7 715 197B2, May $11,2010$.

[10] Y. Sun, F. Wu, and K. Chen, "Semiconductor device packages with integrated heatsinks," U.S. Patent US20 110049 704A1, Mar. 3, 2011.

[11] E. Farsad, S. P. Abbasi, and M. S. Zabihi, "Fluid flow and heat transfer in a novel microchannel heat sink partially filled with metal foam medium," Journal of Thermal Science and Engineering Applications, vol. 6, no. 2, June 2014. [Online]. Available: https: //doi.org/10.1115/1.4025823

[12] C. L. Belady, E. C. Peterson, S. L. Harris, S. A. Belson, and G. W. Williams, "Redundant power beneath circuit board," U.S. Patent US7 791 889B2, Sep. 7, 2010.

[13] X. He and T. H. Hubing, "Mitigation of unintentional radiated emissions from tall VLSI heatsinks using ground posts," IEEE Transactions on Electromagnetic Compatibility, vol. 55, no. 6, May 13 2013. [Online]. Available: https://doi.org/10.1109/TEMC.2013. 2259629

[14] J. J. Casanova, J. A. Taylor, and J. Lin, “Design of a 3-D Fractal Heatsink Antenna," IEEE Antennas and Wireless Propagation Letters, vol. 9, November 9 2010. [Online]. Available: https: //doi.org/10.1109/LAWP.2010.2091104

[15] K. Horiuchi, A. Nishihara, and K. Sugimura, "Multi-objective optimization of water-cooled pinfin heatsinks," International Journal of Heat and Mass Transfer, vol. 81, February 2015. [Online]. Available: https://doi.org/10.1016/j.ijheatmasstransfer.2014.10.057

[16] C. Serafy, A. Srivastava, A. Bar-Cohen, and D. Yeung, "Design space exploration of 3D CPUs and micro-fluidic heatsinks with thermo-electrical-physical co-optimization," in $13^{\text {th }}$ International Conference on Nanochannels, Microchannels, and Minichannels, San Francisco, United States, 2015, p. 10.

[17] G. N. Shilo, E. V. Ogrenich, and N. P. Gaponenko, "Design of finned heatsinks having minimum mass," in International Conference Modern Problems of Radio Engineering, Telecommunications, and Computer Science,, Lviv-Slavske, Ukraine, 2010, pp. 23-27.

[18] M. D. Neumann, "Heatsinks and a spring in a baffle slot between adjacent components," U.S. Patent US7 821 785B1, Oct. 26, 2010.

[19] Z. Ying and Z. Kai, "Numerical analysis and experimental research on finned heatsinks with heat pipes," Cryogenics \& Superconductivity, vol. 2, 2013.

[20] A. S. Chernyshov, H. Yuan, B. Valcu, A. Ajan, and R. B. Acharya, "Recording media with multiple bi-layers of heatsink layer and amorphous layer for energy assisted magnetic recording system and methods for fabricating the same," U.S. Patent US8 605 555B1, Dec. 10, 2013.

[21] L. E. Llano, L. C. Ruiz, D. M. Domínguez, and M. C. Melo, “Design of longitudinal Finned tubes adjusted with the Cesàro curve," Revista Facultad de Ingeniería, vol. 27, no. 48, May 2018. [Online]. Available: http://dx.doi.org/10.19053/01211129.v27.n48.2018.8104

[22] M. Hu, D. Baleanu, and X. Yang, "One-phase problems for discontinuous heat transfer in fractal media," Mathematical Problems in Engineering, vol. 2013, no. 3, January 2013. [Online]. Available: http://dx.doi.org/10.1155/2013/358473

[23] H. Wang, "Fast image fractal compression with graph-based image segmentation algorithm," International Journal of Graphics, vol. 1, 
no. 1, pp. 19-28, Nov. 2010.

[24] J. Pourahmadazar, C. Ghobadi, and J. Nourinia, "Novel modified pythagorean tree fractal monopole antennas for UWB applications," IEEE Antennas and Wireless Propagation Letters, vol. 10, May 2011. [Online]. Available: http://dx.doi.org/10.1109/LAWP.2011.2154354

[25] S. Lin and et al, "A printed log-periodic tree-dipole antenna (PLPTDA)," Progress In Electromagnetics Research M, vol. 21, January 2011. [Online]. Available: http://dx.doi.org/10.2528/ PIERM11080109

[26] A. Espinoza, F. C. Ordaz, E. Ugalde, and R. Femat, “Analysis of a model for the morphological structure of renal arterial tree: Fractal structure," Journal of Applied Mathematics, vol. 2013, no. 12, July 2013. [Online]. Available: http://dx.doi.org/10.1155/2013/396486

[27] F. N. Doubal and et al, "Fractal analysis of retinal vessels suggests that a distinct vasculopathy causes lacunar stroke," Neurology, vol. 74, no. 14, April 6 2010. [Online]. Available: http://dx.doi.org/10.1212/WNL.0b013e3181d7d8b4

[28] K. Bai, C. Meneveau, and J. Katz, "Near-wake turbulent flow structure and mixing length downstream of a fractal tree," Boundary-Layer Meteorology, vol. 143, no. 2, May 2012. [Online]. Available: http://dx.doi.org/10.1007/s10546-012-9700-2

[29] A. Díaz, A. Mosquera, J. L. Endrino, and P. Lafont, “Design and rapid prototyping of dlc coated fractal surfaces for tissue engineering applications," Journal of Physics: Conference Series, vol. 252, no. 1,
Dec 2010. [Online]. Available: http://dx.doi.org/10.1088/1742-6596/ 252/1/012003

[30] A. Bartrés and et al, "Algorithm programming for 3D fractal dimension evaluation," in 2016 Global Medical Engineering Physics Exchanges/Pan American Health Care Exchanges (GMEPE/PAHCE), Madrid, Spain, 2016, pp. 4-9.

[31] S. Kobayashi, T. Maruyama, S. Tsurekawa, and T. Watanabe, “Grain boundary engineering based on fractal analysis for control of segregation-induced intergranular brittle fracture in polycrystalline nickel," Acta Materialia, vol. 60, no. 17, October 2012. [Online]. Available: https://doi.org/10.1016/j.actamat.2012.07.065

[32] K. K. Manesh, B. Ramamoorthy, and M. Singaperumal, "Numerical generation of anisotropic 3D non-Gaussian engineering surfaces with specified 3D surface roughness parameters," Wear, vol. 268, no. 11, May 12 2010. [Online]. Available: https://doi.org/10.1016/j. wear.2010.02.005

[33] X. L. Bin, X. Han, and S. Chen, "Fractal analysis of engineering ceramics ground surface," Applied Surface Science, vol. 258, no. 17, June 15 2012. [Online]. Available: https://doi.org/10.1016/j.apsusc. 2012.03.050

[34] G. Serrano, "Diseño e Implementación de un amplificador de audio en clase $A B$ en un puente de baja potencia," M.S. thesis, Escuela Técnica Superior Ingenierios Industriales Valencia, Universidad Politecnica de Valencia, Valencia, España, 2013. 